\title{
Financing Micro-businesses and the UNCITRAL Model Law on Secured Transactions
}

\section{Introduction}

An overwhelming proportion of businesses in the world are very small, consisting of just one person with no or very few employees. Despite the small size of such businesses, it is extremely important to the economic wellbeing of states that they thrive and grow. In order to achieve this, access to finance is critical. While there have been some positive developments towards this goal, such as Government-run programmes to foster the creation of start-ups (mostly micro-businesses) and to enhance access to finance for smaller enterprises, or the widespread growth of microfinance in developing and middle income countries, ${ }^{1}$ these measures tend to be limited in their operation and usefulness. Secured financing, especially when provided by financial institutions, is necessary for most micro-businesses to achieve their potential, but access to this type of financing is, at present, restricted and, in some situations, non-existent. The legal structure for secured financing provided by the UNCITRAL Model Law can alleviate some of the problems preventing access to secured financing for micro-businesses. This paper examines these problems, and the difference that adoption of the Model Law system could make. It also identifies some areas in which the Model Law is not entirely suitable for the financing of micro-businesses, as well as specific issues which must be addressed by other areas of law and regulation if financing to micro-businesses is to flourish. While the primary focus is on micro-businesses in developing economies, it is suggested that the problems faced by micro-businesses in accessing finance arise even in the more developed jurisdictions, and that at least some of the solutions suggested are appropriate for consideration in all parts of the world.

\section{Defining the scope of the analysis}

\section{a. Definition of a micro-business}

Defining the term 'micro-business' is a difficult task. Economic analysts, governments and supra-national institutions use different definitions for the term, and, often, the category of

\footnotetext{
- Louise Gullifer (Professor of Commercial Law, Oxford University, Fellow and Tutor in Law, Harris Manchester College, Oxford, Holder of 2017 Santander Chair of Excellence at Universidad Carlos III de Madrid, during which time this paper was written) and Prof. Ignacio Tirado (Faculty of Laws, Universidad Autónoma de Madrid).

This paper is the result of the authors' participation in UNCITRAL's Fourth International Colloquium on Secured Transactions, held in Vienna 15-17 March 2017. We are indebted to our co-panelists, Murat Sultanov (World Bank Group) and María del Pilar Bonilla (Signature Regional Law Group and Universidad Francisco Marroquin, Guatemala), for the excellent discussion before, during and after the panel. We are also grateful to the participants in the Colloquium for their insights during the debate.

- This article has been submitted to the Uniform Law Review for publication.

${ }^{1}$ See section 3 a below.
} 
micro-businesses is subsumed in the larger category of Micro, Small and Medium Enterprises (MSMEs) ${ }^{2}$. The typical definition of a 'micro-business' is constructed with figures that indicate the size of a business: most frequently the number of employees, the value of the assets or the turnover of the business. The most commonly used indicator is the number of employees. By way of example, in order for the World Bank to consider a business as a 'micro-business', it must not have more than 4 employees. The EU, however, extends the criterion to 10 employees (and adds the requirement that the business have a turnover below 2 million euro or a balance sheet total of less than 10 million euro) $)^{3}$. The main focus of this paper is to identify the specific characteristics of micro-businesses that may pose challenges to the system envisaged in the UNCITRAL Model Law. The Model Law's main aim is to increase access to finance, especially targeting small and medium sized enterprises (SMEs) ${ }^{4}$; but microbusinesses present challenges that are unique, and that are not shared with SMEs. In many respects, micro-businesses are closer to individuals than to medium-sized businesses. In the light of this, this paper will adopt the World Bank definition (a business with fewer than 4 employees) as a proxy for our analysis.

\section{b. The legal form of micro-businesses}

Micro-businesses can take different legal forms. Often, especially in more developed economies, they are run through limited liability companies and, though less frequently nowadays, by means of partnerships ${ }^{5}$. The use of the corporate form has many advantages

\footnotetext{
${ }^{2}$ MSME is the expression commonly used to designate all non-large businesses. Effectively, its use divides the corporate landscape into two parts: large businesses and others. This division is indeed unhelpful because it clusters over $90 \%$ of all businesses into the same class.
}

Normally, the differences between definitions vary depending on the reason that underlies the need to define the term. Sometimes the definition is ostensibly large to widen the scope of certain public policies (eg, the EU's definition of 'MSME' includes businesses with up to 250 employees, which is a truly large business in many jurisdictions, including middle income EU member states); at other times, stakeholders define 'MSME' with a view to fostering internal control and rationalising their portfolio strategy (eg, banks often define whether a business is in the category of 'MSME' depending on the size of the loan made to that business).

${ }^{3}$ According to the World Bank's MSME country indicator index, the most used criterion to define MSMEs is the number of employees (92\% of the definitions include it), then turnover (49\%) and assets (36\%); and $11 \%$ of 267 analysed definitions include other variables, such as loan size, formality, years of experience, etc. (see E. Gonzales/M. Hommes/M. Mirmulstein, "MSME Country Indicators 2014. Towards a Better Understanding of Micro, Small and Medium Enterprises" (available at www.smefinanceforum.org/sites/all/modules/custom/sme custom/datasites/analysis\%20note.pdf).

According to this source, the most common threshold to define micro-businesses by number of employees is 10 .

A helpful overview of the different methodologies used to define micro-businesses can be found in O.P. Ardic/N. Mylenko/V. Saltane, "Small and Medium Enterprises. A Cross-Country Analysis with a New Data Set", Policy Research Working Paper nbr. 5538, The World Bank, Jan 2011 (the paper can be downloaded at https://openknowledge.worldbank.org/handle/10986/3309).

${ }^{4}$ UNCITRAL Legislative Guide to Secured Transactions (2010) Introduction, paragraphs 2 and 6.

${ }^{5}$ In jurisdictions with codified civil law systems, the use of "commercial" partnerships with unlimited liability was the rule at the time of codification and for decades thereafter. Initially, limited liability was regarded as a privilege, reserved for the large entities, that had to provide high amounts of equity capital. However, the introduction of limited liability for corporate forms with lower capital requirements (società 
for smaller businesses, but it has traditionally also involved high costs (excessive equity requirements, foundation costs, legal formalities, etc.) and this has acted as a deterrent to formality in business practice. Because of this, many countries have created simplified corporate structures, with more flexibility and involving fewer costs ${ }^{6}$. Despite these attempts at improving the vehicle, practice across jurisdictions shows that the benefit of limited liability is severely undermined in the case of micro-businesses. Shareholders and/or directors (the identity of which in the case of micro-entities often coincides) are very frequently required to provide personal guarantees in order to obtain financing, which has the effect of removing the most important benefit from the use of a vehicle with separate legal personality. ${ }^{7}$ Unlike in the rest of the corporate market landscape, in the province of micro-businesses the exercise of business activity without any sort of legal incorporation is, however, still widespread, being particularly prevalent in developing economies ${ }^{8}$. Often, individuals operate businesses in their own name and for their own interest, as "sole/individual entrepreneurs" (or "sole/individual proprietors"). ${ }^{9}$. Generally, the distinct element that defines a sole entrepreneur is the fact that she conducts a stable business activity in the market, openly in her own name, but it is not uncommon for some type of registration to be required ${ }^{10}$. A sole entrepreneur may operate

a responsabilità limitata -Italy-, sociedad de responsabilidad limitada -Spain-, GmbH -Germany-) became an almost immediate success. The use of unlimited liability partnerships is now exceptional, even for the MSME sector. The same is true for common law jurisdictions. For example, in the UK only $8.8 \%$ of total businesses registered for Value Added Tax and/or Pay As You Earn (collection of income tax at source by businesses) are partnerships (which includes limited liability partnerships), while $68.8 \%$ of total businesses are companies (source, 2016 Office of National Statistics, https://www.ons.gov.uk/businessindustryandtrade/business/activitysizeandlocation/bulletins/ukbusine ssactivitysizeandlocation/2016)

${ }^{6}$ Good examples are the German Unternehmergesellschaft, the Colombian Sociedad por Acciones Simplificada, or, generally, the EU's single-member private limited liability company (see Directive 2009/102/EC). Further, the creation of highly flexible, unregulated companies, with limited liability, seems to be a trend nowadays. This is the result of what has been labelled as "unincorporation". For a summary and analysis, see J. McCahery/E. Vermeulen/P. Priydershini, "A Primer on Unincorporation", ECGI Working Paper Series in Law, Working Paper 198/2013.

Concerning the most adequate corporate vehicles to structure micro-businesses, the work of UNCITRAL's Working Group I is especially relevant. Its documents and debates may be found in http://www.uncitral.org/uncitral/en/commission/working_groups/1MSME.html.

${ }^{7}$ Although in some jurisdictions there will also be tax advantages in incorporating.

${ }^{8}$ However, the amount of "sole entrepreneurs" active in fully developed economies is surprisingly high. As an example, in Germany ----; or, in Spain, ----- . In the UK, 'sole proprietors' represented $18.7 \%$ of businesses registered for tax purposes in 2016 (see above fn 5)

${ }^{9}$ These terms are currently used internationally for the classic concept of individual "merchant" present in most commercial codes in civil law jurisdictions and the concept of 'sole trader' used in common law jurisdictions.

${ }^{10}$ Registration as "entrepreneur" is, in some jurisdictions, of the utmost importance. It is frequent that registration is required as a requirement to be bound by certain duties (eg the filing of financial statements, the right to appoint agents with general powers of attorney, etc.) and to enjoy certain rights (eg, access to public funding, to the services of chambers of commerce etc.). Registration may also be required for tax purposes. But the importance of registration is even greater in jurisdictions that have a special regulation for entrepreneurial activity, which is distinct from that applicable to general private parties. This is the case in countries that have separate commercial and civil codes (for example, Spain or Germany). 
the business individually or, more frequently, through one or more employees ${ }^{11}$. The concept of a 'sole entrepreneur' also includes self-employed professionals providing services, whatever the type of activity so long as it is market based. Thus, for example, a lawyer, an insurance agent or a plumber would all be micro-businesses. While some jurisdictions might not consider these as sole entrepreneurs for certain legal purposes, it is difficult to see how their situation would differ from other types of sole entrepreneur in terms of access to finance ${ }^{12}$. In this paper, we consider that, with the exception of exempt property for social reasons, ${ }^{13}$ all the assets of the debtor are available to satisfy all creditors, whatever the type of asset (whether or not acquired or used in the context of the entrepreneur's professional activity) or the origin of the debt (whether incurred to finance a professional activity or simply as a consumer debt). Even in jurisdictions where there is regulatory division between "formal" (often registered) entrepreneurs and other individuals informally operating businesses, the separation of assets does not exist, and, where it does, it is only relevant to the order in which creditors can look to assets to satisfy the outstanding debt, so that creditors whose debts have arisen in the context of the entrepreneurial activity must first exhaust assets used in such activity).

\section{c. The importance of micro-businesses}

The importance of micro-businesses cannot be overstated. In quantitative terms, these businesses represent the vast majority of the total number of businesses in every nation on the planet. The relative importance of their economic output is particularly high in developing and middle income countries, where official figures only show a fraction of the total number of micro-businesses due to the high level of informality ${ }^{14}$.

\section{Chart 1. Source: IFC Enterprise Finance Gap Database ${ }^{15}$}

\footnotetext{
${ }^{11}$ Somewhat surprisingly, some surveys exclude entrepreneurs with no employees from the category of micro-business or treat them as "informal" enterprises (see, for example the World Bank Group's Enterprise Finance Gap Methodology, available at https://www.smefinanceforum.org/data-sites/ifcenterprise-finance-gap). In this paper, all sole entrepreneurs are treated as micro-businesses.

${ }^{12}$ In the European commercial codes of the nineteenth century, professionals were often left out of the special regulation regime envisaged for "entrepreneurs" (rectius, "merchants"). With time, this approach has been abandoned in most jurisdictions.

${ }^{13}$ See further $4 \mathrm{~b}$ below.

${ }^{14}$ The IFC (World Bank Group) reported that, by October 2013, about $80 \%$ of all businesses in developing nations were either informal or had no employees (a total estimate of 300 million enterprises) (see https://www.smefinanceforum.org/data-sites/ifc-enterprise-finance-gap\#field-data-sites-tabs-tab4). Although the data is only approximate, in 2007, India counted about 1.6 million formal MSMEs, while more than 26 million were unregistered. For an interesting overview of the data on MSMEs, see K. Kushnir/M. Mirmulstein/R. Ramalho, "Micro, Small and Medium Enterprises Around the World: How Many Are There, and What Affects the Count", The World Bank/IFC, available at http://www.ifc.org/wps/wcm/connect/9ae1dd80495860d6a482b519583b6d16/MSME-ClAnalysisNote.pdf?MOD=AJPERES.

${ }^{15}$ The chart is an adapted version of a chart included in the presentation of Murat Sultanov, of the World Bank Group, in UNCITRAL's Secured Transactions Colloquium, March 2017 ('MS presentation').
} 


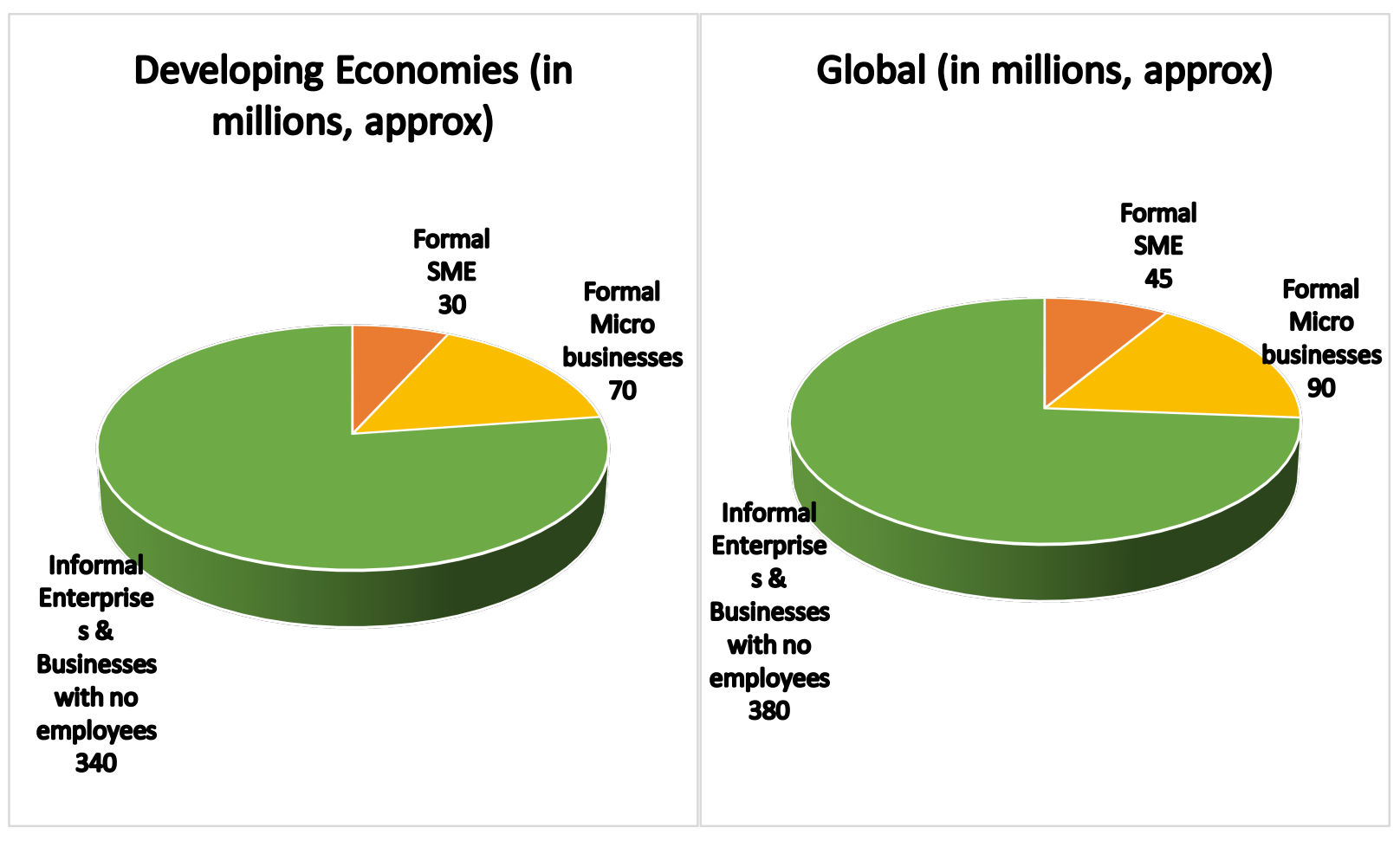

But the quantitative and qualitative importance of micro-businesses is global, and is not limited to less developed economies. In the following chart we show the percentage of micro-businesses out of the total number of businesses in several representative jurisdictions as well as their share of the total work force. A strikingly similar picture is shown in these selected jurisdictions from different continents: around $90 \%$ of all businesses and almost half of the labour force are linked with microbusinesses $^{16}$.

\section{Chart 2. Source: SME Finance/IFC ${ }^{17}$}

\footnotetext{
The presentation is available at http://www.uncitral.org/pdf/english/colloquia/4thSecTrans/Presentations/3Fin2Micr/Microfinance SUL TANOV.pdf.

${ }^{16}$ Businesses with fewer than 10 employees constitute over $93 \%$ of the total amount of businesses in the European Union (see http://ec.europa.eu/eurostat/statisticsexplained/index.php/Structural business statistics overview).
}

According to the World Bank Group, the percentage of the full time labour force involved in microbusinesses in developing nations is around two thirds of the total work force. See https://www.smefinanceforum.org/data-sites/ifc-enterprise-finance-gap\#field-data-sites-tabs-tab-4.

${ }^{17}$ The data for each country can be accessed at smefinanceforum.org , a website of the World Bank Group. The definition of micro-business used is not fully consistent in all the countries included in the 


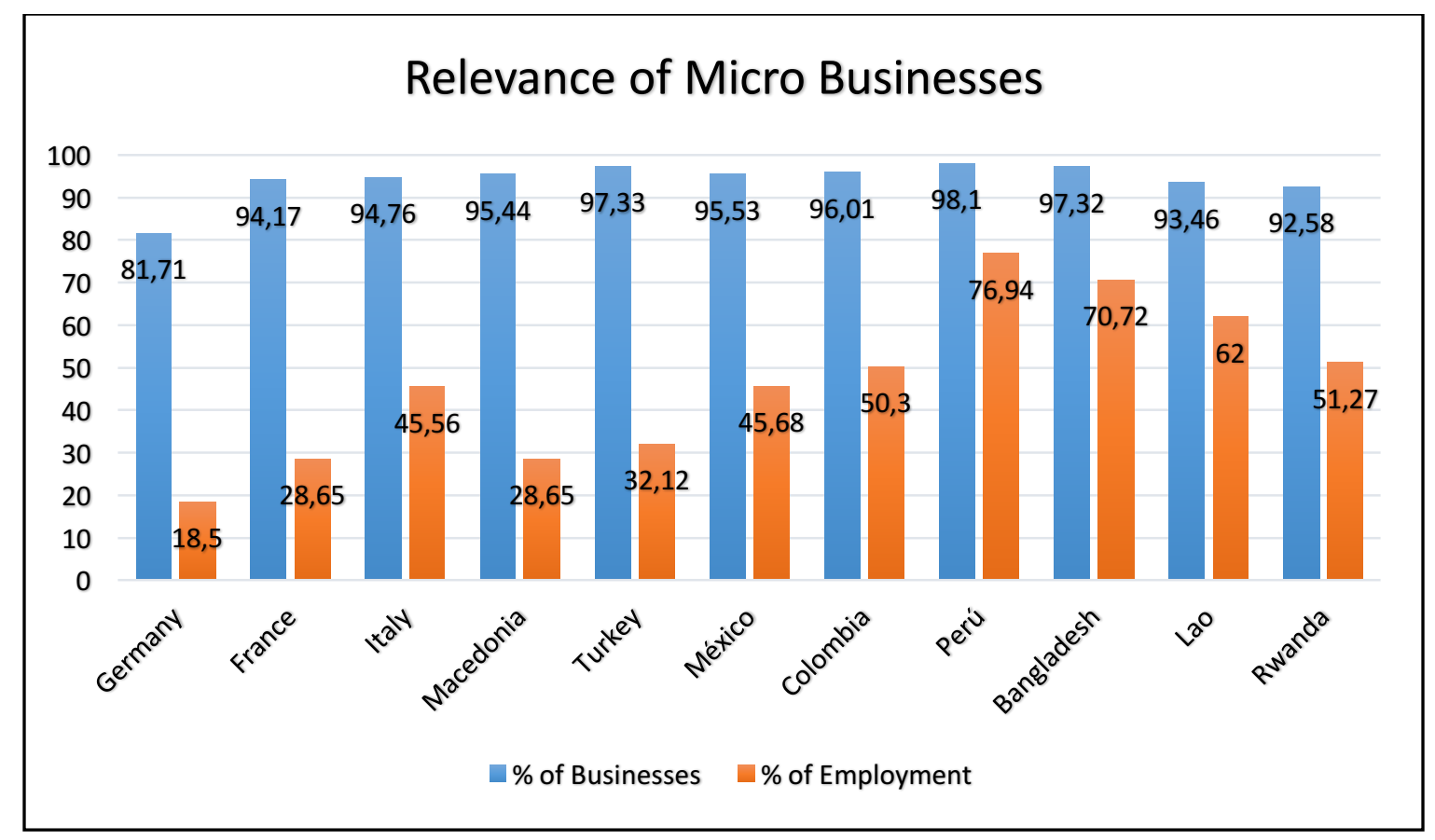

On the basis of these numbers, it is apparent that granting sufficient and affordable access to finance micro-businesses is paramount for any economy to thrive. With very few exceptions, no business starts as a large organisation. Micro-businesses are thus the entry point for entrepreneurialism and are the channel to innovation. The development and growth of smaller enterprises, however, also concerns social development and justice. Start-ups provide access to the market for the young and second chances to more experienced entrepreneurs. Micro-businesses often require small amounts of capital and hence are the vehicles used by the members of society with few resources. Their development is also the key to addressing certain failures of the economic system: those who have more difficult access to the labour market (for example, women or minorities) or those who have lost their jobs can find alternative opportunities in the micro-business sector.

\section{d. The finance gap for micro-businesses}

MSMEs in general have severe problems accessing adequate levels of financial support. Although the problem affects countries with developed markets and, to a greater extent, middle income jurisdictions, it is particularly critical in developing economies. According to data gathered by the World Bank Group, the finance gap for MSMEs (by October 2013) was approximately 2 trillion USD, while, by way of comparison, the amount of all outstanding credit granted to MSMEs was 6 trillion USD

chart. All EU and Latin American countries define microbusiness, inter alia, as having fewer than 10 employees; however, Bangladesh limits the concept to businesses with 9 employees or less, the Popular Republic of Lao to 5 or less, and Rwanda to 3 or less. 
18. The finance gap is even larger in relation to the specific categories of microbusinesses (defined as having up to 4 employees) and to informal enterprises. Over 200 million formal and informal micro-businesses were 'unserved' (that is, they needed credit but had no access to credit) or 'underserved' (that is, they had a loan and/or a line of credit but were constrained as to the amount of available financing $)^{19}$. In the following chart we provide some more detail of the finance gap, as well as information about the type of financing and financial services which are available.

\section{Chart 3. Financial Gap and Types of Financing for Informal Businesses ${ }^{20}$ (informal + no employees)}

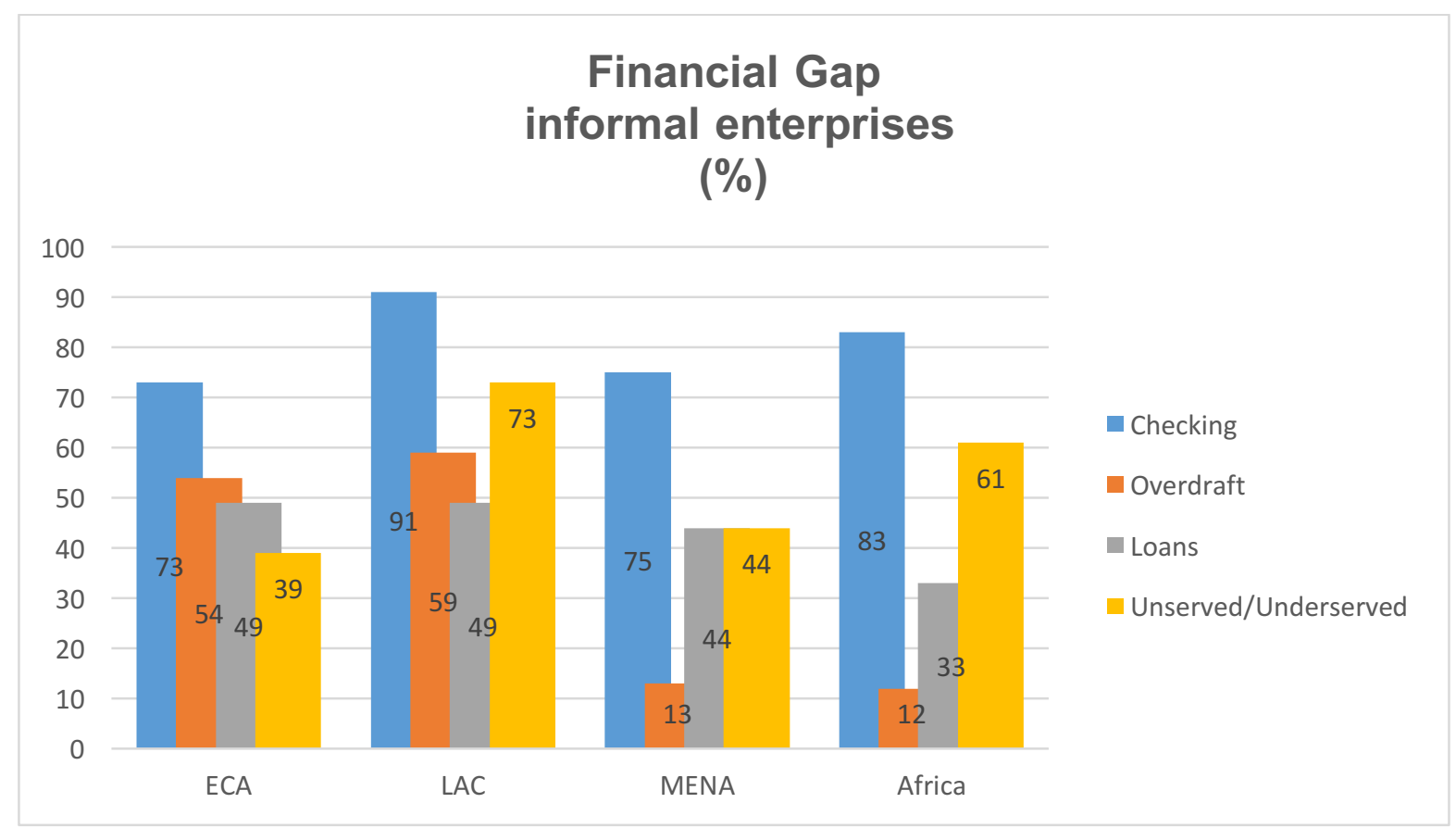

${ }^{18}$ As of March 2017, the amount of unserved/underserved MSMEs in developing economies would range between 2.1 and 2.5 trillion USD, according to MS presentation, see fn 15 .

${ }^{19}$ See https://www.smefinanceforum.org/data-sites/ifc-enterprise-finance-gap. The 'finance gap' in these charts is the percentage of all businesses of the specified category that have no access or insufficient access to credit (as opposed to businesses that do not need more credit or that do not need any credit at all). The numbers reflect the answers to a survey, and are not the result of technical calculations on the balance sheet or business plans of the businesses.

${ }^{20}$ ECA stands for "Europe and Middle East"; LAC for "Latin America and the Caribbean"; MENA for "Middle East North Africa"; and "Africa" includes sub-Saharian Africa.

Data concerning informal enterprises is not always updated to October 2013 and it is gathered through on-site surveys and by indirect sources. See https://www.smefinanceforum.org/data-sites/ifcenterprise-finance-gap. 


\section{Chart 4. Financial Gap and Types of Financing for Micro Businesses}

\section{(1-4 employees)}

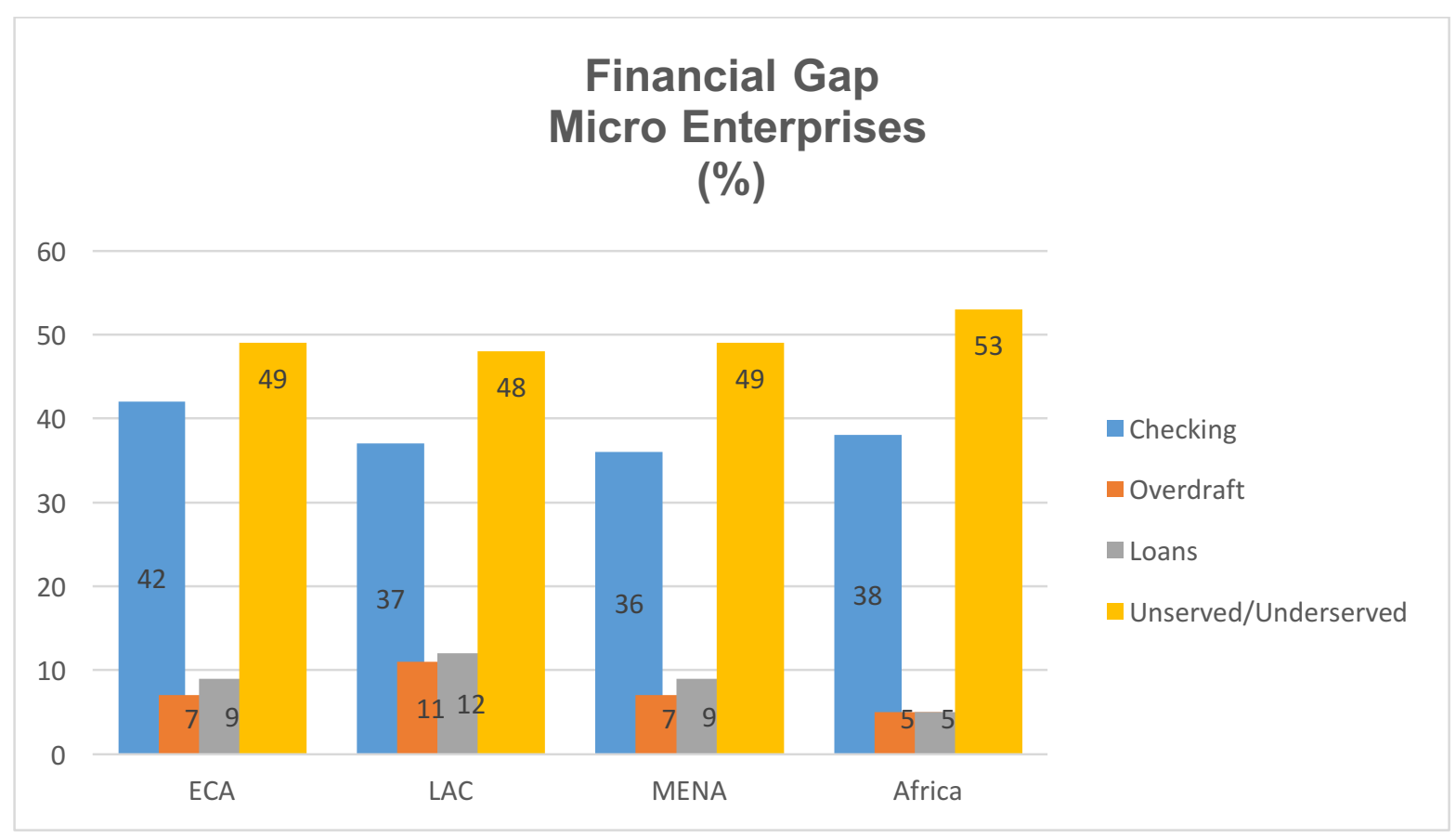

The data displayed above shows the enormous finance gap for micro-businesses as a global problem, affecting all regions included in the chart. The percentage of microbusinesses with no access to finance or with insufficient access to funding is in around or over $50 \%$. The participation of banks in the financing of micro-businesses is also low, considerably lower than their provision of financial support to larger businesses ${ }^{21}$. Frequently, micro-businesses are constrained to operate on the basis of equity finance together with commercial (or trade) credit. ${ }^{22}$ The availability of the former is, for micro-businesses, usually very limited; the latter is volatile and its maturity is short. Because of this situation, other extraordinary financing resources need to be put in place. A classic example is the establishment by Governments of lines of credit, guarantee schemes and other public mechanisms to support access to finance for micro-businesses. Similarly, and often in addition to the Government schemes, associations of micro-businesses and chambers of commerce create mutual guarantee schemes to assist start-ups and small entrepreneurs. Although

\footnotetext{
${ }^{21}$ Microbusinesses have a low demand for flexible, tailor-made loans, and their use of banking services other than loans is limited. This may, in part, help explain the relatively unimportant played by banks in the MSME sector. See J. Glisovic/M. Martinez, "Financing Small Enterprises: What Role for Microfinance Institutions?", CGAP Focus Note nbr. 81, July 2012, pg.1 et seq.

${ }^{22}$ See further section 3c. below
} 
these measures are to be commended, they frequently constitute no more than temporary and insufficient relief for enterprises that are unable to obtain credit in the market through their own means (and hence, to some extent, interfere with an adequate market selection process).

Some of the main reasons why micro-businesses strive to access sufficient financial support are the following:

i. Most micro-businesses do not have real estate to use as collateral. ${ }^{23}$ The lack of real estate is a particular problem in jurisdictions with banking sectors that are either underdeveloped or where competition is limited. This is the situation in many developing and middle income countries, where banks are simply unwilling to lend to micro-businesses (or anyone else, for that matter) unless real estate is provided as collateral to secure the transaction.

ii. The amount and value of movable assets in the possession of microbusinesses is limited, its maintenance is difficult to monitor and its enforcement is complex and costly compared to the value of the assets. ${ }^{24}$ Because of this, creditors in jurisdictions without a well-functioning, cost-effective system of secured transactions are often unwilling to lend against this sort of collateral.

iii. Severe information problems exist in the financing of micro-businesses. The level of formality in such businesses is often low and the information provided to financiers is unreliable. The more underdeveloped the economy, the graver the problem. In jurisdictions with a functioning tax system in place, some microbusinesses must, at least, compile and submit templates with basic financial information at the end of each fiscal year; but, not infrequently, smaller microbusinesses, with turnovers below a certain threshold, are exempt from these reporting duties. Particularly in the case of unincorporated microenterprises, financial accounts are not properly filed and reported. Often micro-businesses have a short life cycle ${ }^{25}$ and the low level of bank debt causes them to be

\footnotetext{
${ }^{23}$ See further section 3c. below.

${ }^{24}$ See section 3c. below

${ }^{25}$ The survival of businesses is directly related to its size, in part precisely because the larger enterprises have more and cheaper access to financial capital (see the classic analysis of D. Audretsch, "New Firm Survival and the Technological Regime", The Review of Economics and Statistics, 1991, nbr. 73 , p. 441 et seq. In the United States, for example, only about $50 \%$ of new small businesses survive beyond the $4^{\text {th }}$ year, and around $40 \%$ beyond the $5^{\text {th }}$ : see, with similar data and results, $B$. Headd, "Redefining Business Success: Distinguishing between Closure and Failure", in Small Business Economics, 2003, nbr. 21, p. 51 et seq; and H. Carder/J. Leatherman, "Small business Survival and Sample Selection Bias", in Small Business Economics, 2011, nbr. 37, p. 155 et seq. Numbers do not seem to be too different in certain developing jurisdictions. In Colombia, a recent analysis shows that more than $50 \%$ of micro-businesses survive after the $5^{\text {th }}$ year: see L. Santana, "Determinants for MicroEnterprises Survival in Bogata: An Analysis using Duration Models", in Innovar, 2017, vol. 27, nbr. 64, available in http://www.scielo.org.co/scielo.php?script=sci_arttext\&pid=S0121-50512017000200005 (document in Spanish). The duration of microbusinesses in developing and middle income economies
} 
invisible to credit reporting systems. All of this hinders access to banking and commercial credit, and increases transaction costs.

iv. On the supply side, a number of factors have the effect that banks fail to carry out proper viability or risk assessments, and that they will only lend against collateral (which, as stated earlier, is scarce). These factors include the unreliability of information mentioned above and the existence of poor credit recovery and enforcement systems. Further, since only small amounts of finance are involved, banks will only make such loans if the transaction costs are commensurately low.

v. There is very considerable asymmetry in bargaining power between professional lenders and micro-businesses. All too often, this allows such lenders to charge excessive interest rates (which has the effect of shortening the chances of survival of micro-businesses) and to request collateral with a much higher value than the amount of financing provided. ${ }^{26}$

The maturity of the credit received by micro-businesses is often short. Minimizing the time for repayment reduces monitoring costs for banks and financial lenders ${ }^{27}$; and trade creditors, such as suppliers and service providers, extend short term credit either because they themselves borrow short term or because, in the case of larger distributors, the imbalance of bargaining power allows them to impose conditions beneficial to them. Due to the small size of the business and the relatively low revenues, the working capital of micro-businesses enterprises tends to be very small. This results in micro-businesses living permanently on the verge of financial distress, with all the negative consequences that such a situation normally entails ${ }^{28}$. The reduced liquidity buffer, the lack (or unreliability) of financial information and the small amounts involved reduce the incentive of creditors to monitor the activity and the financial status of the microbusiness. The problem is not always just a matter of incentives. Entities financing micro-businesses in developing countries often lack tailored risk assessment mechanisms, are deficient in debt management strategies

\footnotetext{
is rather difficult to quantify. The reason is that most of these jurisdictions do not have a widely-used insolvency system and suffer from a low level of formality, and hence many -probably most- of microbusinesses never formally end (they simply de facto cease to trade and disappear).

${ }^{26}$ See section 5

${ }^{27}$ Banks react to the lack of reliable information by reducing the maturity of the loans. See the classic analysis by R. Rajan, "Insiders and outsiders: the choice between informed and arm's-length debt", Journal of Finance 1992, nbr. 47, pgs. 1367-1400; and D. Diamond, "Debt maturity and liquidity risk", Quarterly Journal of Economics, 1991, nbr. 106, pgs. 709-737.

${ }^{28}$ Enterprises under constant threat of defaulting upon payments due in the ordinary course of business find themselves in a weak bargaining position, have difficulties to plan beyond the short term, lose the ability to attract investments in order to grow and often have to dispose of assets in a fire sale, which undermines the value of the business and jeopardises its chances of future recovery.
} 
and often even lack specialised employees to handle the loan portfolio. On the demand side, since micro-businesses have a strong personal and family component, entrepreneurs often postpone adopting any action that will weaken their control of the activity. Because of this, microbusinesses normally do not use timely, value-preserving restructuring options, and, instead, end up in piece-meal liquidations that generate very low returns to creditors. The problem of micro-businesses is, thus, not only one of access to credit, but one that affects the entire lifecycle of credit.

\section{Financing models for micro-businesses}

\section{a. Introduction: the two models used in the financing micro-businesses}

There is a place where general financial institutions do not reach. Paradoxically, this loophole lies not where banks and other financial entities are asked for too much, but where the smallest borrowers apply for too little. Since these borrowers have no other "valuable collateral" to provide other than their own repayment capacity, and, additionally, because of the high levels of informality and very low levels of sophistication, the machinery of ordinary financial institutions becomes too costly and cumbersome for financing to be economic: the overhead costs, including the cost of the risk assessment process, are too great for lending to be a worthwhile activity. As early as the early $18^{\text {th }}$ century, special financing vehicles were created to fill the gap. These vehicles, which initially were just funds created by charitable donations, mushroomed in the 20th century, becoming professional, for-profit financial institutions providing 'microfinance' ${ }^{29}$. Microfinance institutions thrive where there is the greatest need, that is, where there are very undeveloped banking systems together with large sections of the population with very low income. It is, thus, mainly a practice found in developing nations. The banking techniques used in microfinance lending are based on intense proximity between lender and borrower. Collateral is hardly ever required, and loans are granted following an assessment of the repayment capacity or other, more "social", variables (such as reputation and family involvement). The loans are for very small amounts and must be repaid within a short period, although typically the microfinance institution seeks a long-term relationship with its clients. Allegedly because of the high costs involved in the lending process, interest rates charged by for-profit, private microfinance entities tend to be very high (and indeed are higher than the interest rates of the general banking sector). Interestingly, often the number of non-performing loans in the microfinance financial sector are lower than those in the rest of the financial market.

\footnotetext{
${ }^{29}$ A very interesting historic review of the sector can be read in A. Hollis/A. Sweetman, "The Evolution of a Microcredit Institution: The Irish Loan Funds, 1720-1920", The Department of Economics of the University of Toronto Working Paper nbr. UT-ECIPA-ECPAP-96-01, January 1996, passim.
} 
However, microfinance institutions have also been subject to criticism ${ }^{30}$. The high interest rates charged and the limited scope of microfinance, both functionally and geographically, make it insufficient to cover fully the finance gap which exists in relation to micro-businesses, as discussed above. ${ }^{31}$ Nowadays, technological and institutional improvements, as well as new forms of secured credit, have paved the way for a much-needed increase in the ability of micro-businesses to obtain finance from the general financial sector. We shall devote the following sections to the analysis of these mechanisms which have the potential to bridge the finance gap.

\section{b. Collateral available for micro-businesses}

This section examines the type of collateral that is available for micro-businesses to provide to lenders and to other providers of finance. Obviously, this is highly contextspecific. One variable, for example, is the type of finance which is being sought. For example, micro-businesses may seek to finance the acquisition of a specific asset (usually equipment), the acquisition of inventory or cash flow. Different types of collateral are appropriate for different types of finance. In the context of acquisition finance, ${ }^{32}$ where the finance is to enable the business to acquire a piece of equipment, the equipment itself will usually serve as collateral under a leasing, hire purchase or conditional sale agreement. Similarly, where the business is acquiring raw materials or stock in trade, these may be financed by the sale being on credit terms, namely, trade credit. In some jurisdictions, the seller will often be protected by a retention of title clause or equivalent (so that the items being acquired act as collateral), while in other jurisdictions it is more common that the transaction will be unsecured and structured using post-dated cheques, bills of exchange or promissory notes. In this section what is primarily examined is the availability of collateral for a bank making a loan to the business, which could either be a revolving facility such as an overdraft or a term loan.

For most lenders, the best collateral is real estate. However, a micro-business is very unlikely to have real estate available to be given as collateral. ${ }^{33}$ This may be because the sole entrepreneur or guarantor is not willing to mortgage their home, or, which is more likely, because it is already mortgaged in favour of the bank that financed its acquisition. Moreover, many individuals will not own real estate at all. If real estate is available, it is likely to be of much greater value than the amount of the loan, so that

\footnotetext{
${ }^{30}$ E.g., see M. Duvendak/R. Palmer-Jones/J. Copestake/L. Hooper/Y. Looke/N. Rao, "What is the evidence of the impact of microfinance on the well-being of poor people?", EPPI Centre, Social Science Research Unit, University of London, Aug. 2011, available at https://www.givedirectly.org/pdf/DFID microfinance evidence review.pdf.

${ }^{31}$ See section $2 d$.

${ }^{32}$ Also called asset finance

${ }^{33}$ See also section $2 \mathrm{c}(\mathrm{i})$ above.
} 
the loan would be heavily overcollateralised ${ }^{34}$ and the transaction costs would outweigh the benefit of the loan. ${ }^{35}$ Thus, any available collateral will have to be moveable property.

Ideally, moveable property offered as collateral for a loan to a micro-business would meet all, or most, of the following conditions. First, it should be easily valued, so that the lender can assess that it covers the amount at risk with a suitable haircut, and the borrower can make sure that it is not too heavily overcollateralised. Secondly, the initial processing of the transaction should be low cost and speedy. Thirdly, it should not be too easy for the borrower to dispose of the collateral without the consent of the lender (although some ability to dispose may be necessary, depending on the type of collateral). Fourthly, it should be easy, quick and cheap to enforce against it if there is default. Thus, liquid collateral is best as the value is easily realised, but it should also be possible to take possession or control speedily so that the value can be realised.

Of course, legal rules and infrastructure creating available markets have a part to play in this as well as the nature of the collateral itself. The system provided by the UNCITRAL Model Law incorporates many features which enable some of these conditions to be met. Thus, for example, a cheap, quick, effective registration system for security rights, such as that provided for under the Model Law, enables the initial transaction costs to be kept low, and also enables lenders to ensure they have priority over other claims to the collateral, since they can search for previously registered interests, and enables a lender to protect itself by registration. Moreover, the Model Law enables lenders to take security over all types of assets, including future assets. The category of 'future assets' includes assets which the business will purchase, produce, grow or otherwise acquire in the future, and therefore includes not only equipment but also inventory, receivables and cash, over which it is not easy, or even possible, to take security under many existing legal systems. Thus the Model Law system increases the types of available collateral which can be used. Moreover, it provides an effective and cheap system of enforcement, including out of court enforcement. $^{36}$

In reality, though, the main limit on collateral which can be offered by a micro-business is practical availability. This will vary enormously depending on the nature of the business, but certain categories can be enumerated and some examples given. First, the business may have tangible assets used as equipment (in a broad sense). These can be acquired either by leasing or by other forms of functional secured lending, such

\footnotetext{
${ }^{34}$ MS presentation (fn 15), based on 'A study of collateral options for microfinance loans in Pakistan,' (PMN, 2012)

${ }^{35}$ C. Miller, 'Agricultural Finance' in the New Microfinance Handbook, WBG, 2013 at page 233.

${ }^{36}$ See Model Law, chapter VII. Some types of out-of-court enforcement, such as the taking of possession of goods, requires the written consent of the grantor, which will typically be given in the security agreement, see Article 77(2) and Guide to Enactment para 424. [note: needs to be checked when final version $\mathrm{GtE}$ is published]
} 
as hire-purchase agreements (acquisition finance). ${ }^{37}$ This, of course, means that they are not available as collateral to be used for other types of financing. Under the UNCITRAL Model Law, however, acquisition finance is treated as secured lending, so to the extent that the value of equipment exceeds the amount due, that surplus value can be used as collateral for new finance. Secondly, the business may own inventory which has not been acquired on credit on retention of title terms ${ }^{38}$, either because such terms are not used by suppliers or because they are not purchased but acquired in other ways, for example, agricultural products which are grown or bred ${ }^{39}$ Such inventory can be given as collateral. Thirdly, the business may have receivables if it sells goods or provides services on credit, which could be the subject of receivables financing (that is, a sale of receivables to a discounter or factor) or of a security interest. ${ }^{40}$

However, both inventory and receivables may not meet the criteria set out above for suitable collateral if, as is often the case, the micro-business does not have sufficient accounting records to prove the existence of these assets. As mentioned above, many micro-businesses are not required to keep accounting records by the state, while larger businesses would have to do so for tax purposes and because accounts are required for registered corporations. ${ }^{41}$ Without the incentive of mandatory record keeping, and because of the cost, micro-businesses are unlikely to have even the limited infrastructure required to record purchases and sale to the level of accuracy required by financial institutions.

Fourthly, the individual or individuals who run the business may have savings which they do not (or cannot) disrupt to spend on the business but which are available as collateral for a loan. This could be cash in a deposit account, which may be required to be saved by the lender, ${ }^{42}$ or it could be a tangible asset, such as gold jewellery,

\footnotetext{
${ }^{37}$ For example, Tugende, an asset finance company, funds the acquisition of motor cycle taxis in Kampala by the use of hire purchase agreements (MS presentation slide 17 (see fn 15)) and bee hives (including the bees) are acquired under a similar scheme (based on an annual leasing contract with an option to purchase) in Kenya funded by KDA (MS presentation slide 19 (see fn 15)

${ }^{38}$ Inventory obtained on retention of title terms is not available as collateral for other financing. Under the Model Law a junior ranking security interest can be given over such assets, but there is unlikely to be enough surplus value in the assets to make this worthwhile.

${ }^{39}$ An example of the former are crops which are often given as collateral by granting a security interest over a warehouse receipt produced by the warehouse in which harvested crops are stored. An example of the latter is the use of present and future turtles bred in turtle farms in China as collateral given to credit providers such as Jingshan Country Rural Credit Cooperative (MS presentation slide 20 (see fn 15)).

${ }^{40}$ This form of financing can also take place higher in the supply chain, thus enabling raw materials to be supplied on credit to the micro-business, see, for example, in the context of the agricultural value chain, C. Miller, 'Agricultural Finance' in the New Microfinance Handbook, WBG, 2013 at page 240.

${ }^{41}$ Section 2c.

42 J. Ledgerwood and J. Earne, 'Credit', at page 217 and I. Mas, 'Beyond Products: Using Infrastructure Customer Experiences on Mobile Phones' at page 314 in the New Microfinance Handbook, WBG, 2013.
} 
which is a very common form of saving in some parts of Pakistan and India and which can be provided as collateral by way of possessory pledge. ${ }^{43}$

\section{c. Guarantees (given by related parties)}

Experience across all types of jurisdictions shows that microbusinesses are very frequently requested to provide personal guarantees to obtain credit. Shareholders and/or directors, who are often the same person, guarantee the debts of the legal entity, and family members and other related parties do the same with regard to individual entrepreneurs. Lenders (mainly financial lenders) often require guarantees in addition to the provision of collateral. No system of access to finance for microbusinesses would be complete unless the regime of secured transactions is made consistent with the regulation of personal guarantees.

Guarantees enhance the assets available for repayment and reduce the borrower's moral hazard by aligning incentives ${ }^{44}$. These effects cause a reduction in the risk of lending, and hence increase the willingness of lenders to provide finance. However, the provision of guarantees effectively means that the business no longer has limited liability, and default often causes dramatic financial problems in the households of the individuals involved. Rules need to be enacted to coordinate the resultant insolvency proceedings of the guarantor and the micro-business ${ }^{45}$, as well as, preferably, out of court solutions operating at a pre-insolvency stage, to ensure a consistent regime of debt discharge. Moreover, rules are needed that tackle abusive use of guarantees 46

\section{Issues arising in relation to the Model Law and possible solutions}

Generally speaking, the UNCITRAL Model Law creates a system that is particularly good for the financing of small businesses: although it applies to all business (and consumer) finance, it clearly works particularly well for non-financial SMEs, and, because it enables security to be given over any kind of asset, as well as all the assets

\footnotetext{
${ }^{43}$ Gold-backed loan products have been developed, for example, by Tameer Microfinance Bank in Pakistan and Kshetriya Gramin Financial Services in India MS presentation slide 16 (see fn 13)).

${ }^{44}$ See A. Katz, "An Economic Analysis of the Guarantee Contract", The University of Chicago Law Review, 1999, nbr.66, pg. 47 et seq. In line with this type of analysis, see also D. Baird, "Security Interests Reconsidered", Virginia Law Review 1994, nbr. 80, pgs. 2249 et seq.

${ }^{45}$ On the abuse of personal guarantees for corporate business and how pre-insolvency (and insolvency) law may solve the problem, see D. Hahn, "Velvet Bankruptcy", in Theoretical Inquiries in Law, 2006, vol. 7, available at http://www7.tau.ac.il/ojs/index.php/til/article/view/600.

${ }^{46}$ For example, the German Constitutional Court (followed by the civil law section of the Supreme Court) has rendered the guarantee of a related person unenforceable, when such person has no relevant assets or income (on the grounds that the initial guarantee is deemed as taken abusively with a view to "harnessing" the borrower's behaviour). CITE
} 
of a business, it could facilitate the financing of micro-businesses as discussed above, and would remove many legal obstacles to such financing. There are, however, some specific areas in which it is likely to work less well, because of the nature of both the financing and the businesses. There are two main characteristics of financing of micro-businesses which are likely to cause problems. One is that they are often do not use the corporate form, and are likely to be sole entrepreneurs, or that if the corporate form is used, there is little distinction between the company and the individual running the business. The other is that the amounts lent are very small, and therefore, to make lending economic, transaction costs needs to be very low indeed. Bearing these two characteristics in mind, three specific issues are discussed in this section.

\section{a. Notification}

There are a number of situations in which the Model Law requires a notification to be sent to the grantor. ${ }^{47}$ Apart from in Art 15(2) (which specifies that the notice is to be sent to the registered address of the grantor unless the secured creditor knows of a more recent address) the Model Law does not specify in detail to where the notification should be sent. This is particularly true of the out of court enforcement provisions. ${ }^{48}$ We suggest that, in the case of micro-businesses, clarification and some mandatory rules are needed. If secured creditors are unsure that notifications given in relation to out of court enforcement can be given quickly and easily, and will be effective, this will affect their decision to extend secured credit to micro-businesses under the Model Law system, since enforcement may be challenged in court on the ground that the grantor was not notified. Court challenges invariably increase delay and costs.

If the grantor is a company, it will have a registered office to which a notice can be sent. $^{49}$ However, particularly in the case of micro-businesses, at the time of enforcement, quite often the business will not operate from the registered office, and there may no longer be individuals associated with the business at that address. Therefore, it would be advantageous to clarify that if a notification is sent to the registered office, the company must be deemed to have received it. If electronic notifications are permitted, which is likely to be the case with any modern

\footnotetext{
${ }^{47}$ For example, Art 15(2) Registry Provisions (secured creditor must send grantor the notification of registration it receives from the registry), Art 77(2)(b) (secured creditor must give grantor notice of default and of its intention to take possession of the collateral), Art 78 (4) (secured creditor must give, inter alia, grantor notice of its intention to dispose of the collateral), and Art 80(2)(a) (secured creditor must send to, inter alia, grantor any proposal to acquire the collateral itself. Some of these notifications must also be given to other people eg a debtor (such as a guarantor) if different from the grantor, who might, of course, also be a natural person and to whom the argument in the text would then apply.

${ }^{48}$ Arts 77 (2)(b), 78(4) and 80(2)(a).

${ }^{49}$ And if the registered office changes, this change should appear on the companies register.
} 
implementation of the Model Law, we suggest that the scheme proposed below for individuals should also apply to companies.

If the grantor is an individual (a sole entrepreneur), his or her home address may well change reasonably frequently and the secured creditor will not necessarily know about this. The same is true of an individual's email address ${ }^{50}$. While, in the context of larger transactions, it might be worth the parties bargaining ex ante to set up a system to deal with notification, this will be too costly for the very low value financing we are considering here. A mandatory system is needed, although, perhaps, one that can be modified by agreement between the parties. It needs to be simple, and effective. For example, in relation to a sole entrepreneur (or a company), a system could provide that details of the means of notification are captured at the inception of the transaction, either as part of the registration process or by some other means. Further, a duty to update these details, using easy to use technology, could be imposed on the grantor with the result that enforcement consequences flow from notification having been given to the last address stored on the system. ${ }^{51}$ Under this system, the grantor has a strong incentive to update, otherwise she will be deemed to have received a notification even though it was not in fact actually received by her. The system could also include a backstop so that if the delivery of the notification to a postal or email address is objectively unsuccessful, then notification can be effected by serving a notice publicly in a publicly accessible institution. ${ }^{52}$ The same system could apply to other debtors or grantors, such as guarantors, who are, in the context of microbusinesses, also likely to be individuals. ${ }^{53}$ The Model Law rules as to notification are, of course, part of the balancing of interests between the ability of a creditor to enforce effectively (and out of court) and the protection of a debtor: this balance may be different where the debtor is an sole entrepreneur or guarantor. Having said this, if the rule is clear, and updating is easy, the scheme suggested may strike the right balance between protection and reduction of cost. The question of balance is more difficult if contractual modification of the mandatory scheme is permitted, since there is then the possibility that a party with superior bargaining power would be able to impose an unbalanced regime on the weaker party. In the case of micro-businesses, this is a particular danger because of the disparity in the sizes of lender and borrower. $^{54}$

\section{b. Enforcement}

There are two main issues relating to enforcement which arise where a business is very small. In the case of a sole entrepreneur, or a guarantor who is an individual,

\footnotetext{
${ }^{50}$ If electronic notification is permitted under the registry regulations enacted.

${ }^{51}$ Although a backstop for emergencies would probably be needed.

${ }^{52}$ Which could also be effected electronically if circumstances permit.

${ }^{53}$ See section 3c.

${ }^{54}$ See section 5 .
} 
there will need to be some limits on what can be seized by the secured creditor. Even if a security interest over all assets is given, in most jurisdictions, certain assets, deemed necessary to live with dignity, are protected at law from seizure by execution creditors. ${ }^{55}$ The same protection is necessary even where they have been given as collateral. Therefore, enforcement of collateral should be only against those personal assets which are not protected at law. At present this is not enshrined in the provisions of the Model law dealing with out of court enforcement, ${ }^{56}$ although if enforcement takes place through the court ${ }^{57}$ or the insolvency system, the court may impose the protection mentioned. Any implementation of the Model Law would have to be subject to these protective provisions of national law, and this needs to be clear to creditors from the start so that they know what assets will be available on enforcement. That is not to say that personal assets cannot be used as collateral at all. As mentioned above, non-essential personal assets such as gold jewellery can be effectively used as collateral for the financing of a micro-business. ${ }^{58}$

In addition, the out-of-court remedies provided in the Model Law may be too complicated and costly for very low-value loans. In relation to enforcement of security rights securing very small loans, a simplified out-of-court procedure may be needed with some protection for the debtor built in. Moreover, it may be necessary to move towards a "small claims" court model, to facilitate enforcement by means of predesigned templates with limited access to appeal or contradiction and/or to consider the use of Alternative Dispute Resolution or Online Dispute Resolution as alternatives to court procedures.

\footnotetext{
${ }^{55}$ Such "exempt property", which typically only exists for individuals, comprises non-seizable assets that cannot be foreclosed upon on social protection grounds. Often, the non-seizable property will consist of working instruments, the bed and basic home furniture, basic clothing, etc. More importantly, in many jurisdictions wages up to a certain amount (usually related to the minimum salary) will not be seizable (ie, future receivables of the sole entrepreneur). But non-seizable property is to be determined at the moment of enforcement, not at the moment of creation of the security right. There is no $a b$ initio exempt property. This is because assets are not, per se, exempt, but only when a certain context of the owner's personal poverty exists; and it is at the enforcement stage when the existence of the social context is to be ascertained (so, for example, a person may grant a security right over his bed, or over his future wages, and only if, at the moment of enforcement, the bed is the grantor's only place to sleep or wages are his only source of income may enforcement be excluded). As examples of this type of regimes, see Germany's s. 850 Zivilprozessordnung or arts. 605 et seq of Spain's Ley de Enjuiciamiento Civil. This protection applies even within insolvency proceedings (see, generally, UNCITRAL's Legislative Guide on Insolvency Law, Part II, 2, A.3).

${ }^{56}$ Article 73(3) of the Model Law states that the exercise of a secured creditor's out of court enforcement rights is determined by the provisions of the Chapter of the Model Law on enforcement (ch VII), ie not, without more, subject to the rules of the enacting State on the protection of individuals as discussed in the text.

${ }^{57}$ Art 73(2)

${ }^{58}$ See $3 b$ above.
} 


\section{c. Security over a bank account for a third party lender}

A very small business is unlikely to have a bank account, but a lender might well insist on this in order to make sure that the money the business receives does not just get spent or lost without the secured party having some control over it. While the Model Law enables a creditor to obtain a security right in a bank account relatively easily, there are some aspects which are complicated and which would, at the very least, need to be carefully explained to both lender and borrower in the context of financing a micro-business. In relation to the money in the account, the lender would want priority over the bank with whom the account is held. Under the Model Law, there is only one way to do this: the account must be in the name of the lender: ${ }^{59}$ this may not be obvious to someone unfamiliar with this system. Secondly, there needs to be a balance between the need of the micro-business to use some of the cash to run its business and the desire of the secured creditor to make sure some of it is there if there is a default. The Model Law has two relevant provisions. The grantor's ability to run its business is aided by art 47(6) which protects recipients of payments who do not have knowledge of any breach of the security agreement. The secured creditor is permitted to withdraw from the bank account at any time if the grantor consents, ${ }^{60}$ which could enable it to keep the funds in the account low and force the grantor to ask permission to borrow more money when it wants to make payments. These two provisions do not really amount to guidance as to the best agreement for parties to the financing of a micro-business to enter into, especially not as to where the balance is struck. Firmer guidance would be necessary for those involved in low value transactions, where individual bargaining is neither possible nor cost-effective.

\section{d. Guarantees and the Model Law}

The UNCITRAL Model Law does not expressly cover guarantees, and there is no guidance in the legislative guide on the interrelation between the law of guarantees and the law of secured transactions. There are certain very specific points of interaction which ought to be addressed. First, guarantors frequently give security for their obligations under the guarantee. ${ }^{61}$ Thus, the points made in subsections $4 a, 4 b$ and $4 \mathrm{c}$ also apply to guarantors as security providers. Further, guarantors who are not paid for the giving of the guarantee, and who are not in a position to bargain for their own protection, require protection from the general law ${ }^{62}$. One aspect of this protection is typically that a guarantor who pays off the secured debt is subrogated to the secured creditor's rights in relation to the collateral, including the right to enforce.

\footnotetext{
${ }^{59}$ Art 47(2) and (5) (which gives protection against the bank's right of set-off). A control agreement under art 47(4) is too complicated for this level of financing, and, in any event, does not give priority over the bank.

${ }^{60}$ Art 82(2)

${ }^{61}$ This is reflected in the definition of 'debtor' and 'grantor' in the Model Law art 2.

${ }^{62}$ See, also, the reflections in section 2 (d) above.
} 
However, the complicated enforcement procedures under the Model Law, ${ }^{63}$ are not suitable for use by individual guarantors, who could find themselves subject to liability to other parties for not having followed the correct procedures. To bolster the protection from this right of subrogation, a secured creditor should owe an obligation to a guarantor to preserve the collateral and its rights over it. Thus, for example, a secured creditor should be under an obligation to perfect its security right so as to preserve the priority of that right for the benefit of a guarantor, and should file an amendment notice identifying the guarantor as the secured creditor if the right of subrogation arises. ${ }^{64}$ While these obligations may arise as a matter of the general law of guarantees, their content is strongly influenced by the detailed provisions of the Model Law. Individual guarantors of the debts of microbusinesses not only need to know and understand the obligations owed to them, there also needs to be an effective way of enforcing breach to incentivise compliance.

\section{Other issues affecting access to finance for micro- businesses}

In the previous sections we have reviewed some of the specific issues that may arise concerning micro-businesses from the implementation of a Model Law-type system. But the Model Law, as a stand-alone piece of legislation, is not sufficient to create a legal framework where micro-businesses may access enough credit under adequate conditions. Other branches of the law need to be adapted to generate a suitable and enabling legal environment for micro-businesses. Debtors of a very small size, of low sophistication and with poor financial information, together with modest amounts of credit requested comprise a cocktail that is hard for most participants in the financing market to digest. Legislative action is necessary to generate the correct incentives for the relevant stakeholders in order to bridge the gap between financing needs and credit availability.

Micro-businesses often borrow from financial institutions or larger commercial creditors. The difference in size results in unequal bargaining power. Lenders find themselves in a position where they can unilaterally define the terms of the transaction which, in the best of cases, leads to the debtor having to choose between the best of two evils, and, in the worst case (when no alternative is available), the debtor has no choice at all. Frequently the interest rates are too high, especially in cases of default. Contractual terms that only benefit the lender are also commonplace: possible examples are abusive enforcement clauses, biased definitions of what constitutes default or the imposition of unreasonable jurisdiction clauses (that is, where the jurisdiction is not linked to the place of the transaction in any way). Another classic reflection of the inequality in bargaining power is the request by the lender for personal

\footnotetext{
${ }^{63}$ See sections 4(a) and 4(b) above

${ }^{64}$ See art 16 Model Registry Provisions and para 189 Guide to Enactment.
} 
guarantees by related persons, when the latter have no or few assets (and the lender is aware of this). Legislators must tackle these issues by making the playing field more level and avoiding abusive behaviour (for example, by controlling certain clauses, limiting default interest rates or monitoring creditor behaviour by regulation).

The financial lender's behaviour towards risk raises regulatory issues. Again because of the small size of the loan and the debtor, financial institutions do not always conduct proper risk assessment analysis. At the origination of credit, the viability of the business is either not properly considered or is directly ignored. These features become more marked the more underdeveloped the relevant economy. ${ }^{65}$ Banks in such situations, often with the consent and even active cooperation of their supervisors, will only lend against collateral, irrespective of the potential of the business. This constitutes "bad banking" and is particularly serious where microbusinesses have little or no collateral to give. Moreover, the inequality of bargaining power, again, often with the cooperation of financial supervisors, leads to the frequent overcollateralization of loans. In developing jurisdictions, it is not infrequent to find loan-to-value ratios of $200 \%$ and above. Naturally, this undermines credit and hampers the chances of micro-businesses to access credit and to, therefore, thrive. Another area where legislators have to take decisions concerns the passivity of banks after the origination of credit. The risk of the loan is poorly monitored after origination (if at all), and few banks are prepare to engage in proper restructuring negotiations when default is approaching: either an automatic rescheduling takes place (with the inherent risk of "evergreening") or the creditor merely waits for default to occur and forecloses on the collateral. The consequences of the latter is the destruction of viable businesses, in the latter case, and, of the former, mistrust in the reality of the balance sheet of banks.

\section{Conclusion}

This paper has drawn on the very significant impact of microbusinesses on the world economy to show the importance of access to finance to the health and growth of such businesses. There are a number of factors which inhibit financing to these businesses, such as the lack of adequate records and information to enable due diligence to take place, the small size of the loans required, which makes the transaction costs proportionately more expensive than in larger loans, and the fact that microbusinesses tend not to have available the types of collateral traditionally favoured by financial institutions. The legal system of secured financing introduced by the Model Law can help address many of these points, since security can be taken over all types of collateral, the registration system aids certainty and reduces costs, and the availability of quick and cheap enforcement, including out of court enforcement, is likely to encourage lenders to accept different types of collateral, and to lend more cheaply.

${ }^{65}$ Both in respect of the banking sector and the non-financial economy, 
Certain features of lending to microbusinesses, however, require special treatment, both from the general legal and regulatory environment, and from the Model Law, which is primarily targeted at lending to small and medium sized enterprises rather than tiny microbusinesses. Although some microbusinesses are structured in a corporate form, in reality it is individuals which are exposed to unlimited liability, whether as sole traders, as director or shareholder guarantors of the corporate liabilities, or as family or friends of the entrepreneur who act as guarantors of the liabilities of the business. While some risk-taking is to be encouraged, these individuals also need some protection from the law. For example, not all personal assets should be able to be the subject of enforcement of collateral, and freedom of contract may need to be tempered due to the vast inequalities in bargaining power. Moreover, some of the Model Law processes do not apply easily to individuals, such as the requirements of notification and the somewhat complicated processes of enforcement and the taking of security over bank accounts. Further, the very small size of the loans means that even the relatively cheap procedures of the Model Law may be too expensive or complex for this market, and also that financial institutions may rely too heavily on collateral, and not assess the risks of lending and the viability of the business properly.

Having identified these and other relevant issues, this paper makes some tentative recommendations as to how they can be overcome, by some microbusiness specific amendments to the Model Law, by some further guidance as to the operation of the Model Law in this area and as to regulatory and other legal developments which could ameliorate some of the wider problems. 